\title{
“TRANS-FORMAÇÃO” POR PRÁXIS DIALÓGICA ARTÍSTICA - UMA ESTRATÉGIA DIDÁTICA TRANSDISCIPLINAR NA FORMAÇÃO DOCENTE À EDUCAÇÃO PROFISSIONAL
}

\author{
"TRANS-FORMACIÓN" EN LA PRAXIS DIALÓGICA ARTÍSTICA \\ - UN TRANSDISCIPLINARIO ESTRATEGIA DE ENSEÑANZA EN PROFESORES \\ DE FORMACIÓN A LA EDUCACIÓN PROFESIONAL
}

\section{"TRANS-FORMATION" IN PRAXIS DIALOGIC ARTISTIC - A TEACHING STRATEGY TRANSDISCIPLINARY IN TRAINING TEACHERS TO PROFESSIONAL EDUCATION}

\section{Paulo Corrêa MENDES ${ }^{1}$}

RESUMO: Este artigo socializa parte dos resultados de uma pesquisa prática na formação docente transdisciplinar à Educação Profissional. Em específico, recorte da utilização de Estratégia Pedagógica - Práxis Dialógica Artística, articulando norteadores Didáticos Transdisciplinares e pressupostos metodológicos para o desenvolvimento de Competências Profissionais. O objetivo central dessa reflexão foi verificar a eficácia da referida estratégia à formação do sujeito cognoscente nas dimensões da vida à vida. $\mathrm{O}$ cerne investigativo partiu de resposta à hipótese: Qual a eficácia da estratégia didática da Práxis Dialógica Artística aplicada à formação integral do ser humano? Estudo realizado durante curso de Capacitação Docente Transdisciplinar, para a docência em variados cursos profissionalizantes, particularmente, nas áreas de design, comunicação e artes visuais, ofertados por instituições no Distrito Federal e entorno. Pesquisa-ação idealizada e fundamentada nas interconexões do pensamento complexo (Edgar Morin); da abordagem transdisciplinar à educação ecossistêmica (Maria Cândida Moraes, Humberto Maturana e Patrick Paul); da pedagogia do diálogo (Paulo Freire); nos princípios à Educação do século XXI, aboradados nos relatórios da UNESCO, para o processo de aprendizagem e que se referem aos saberes: aprender a aprender, aprender a fazer, aprender a conviver e aprender a ser (Jacques Delors); entre outros colaborativos estudos científicos. Esta estratégia é mais uma eficaz práxis pedagógica transdisciplinar, que busca propiciar a consciência da "trans-formação" do sujeito aprendente, em articulação aos fundamentos técnicos e científicos, capacidades técnicas e, capacidades sociais, organizativas e metodológicas. Portanto, colaborativos saberes para enfrentar incertezas e garantir a perpetuação de um mundo complexo - interligado e repleto de paradoxos.

Palavras-chave: Estratégia Didática Artística. Formação Docente. Ensino por Competências. Educação Profissional. Docência Transdisciplinar.

\footnotetext{
${ }^{1}$ Mestrando em Educação - UCB. Licenciatura Plena - Formação Pedagógica de Jovens e Adultos - UNISUL. Graduado em Ciências Econômicas - UCB. Membro do grupo de pesquisa ECOTRANSD/CNPq: ecologia dos saberes, transdisciplinaridade e educação. Especialista em Design Editorial e Gráfico pelo Instituto Europeu de Design e IESB. Docente de cursos de Educação Profissional no SENAC DF. Atuou como coordenador, supervisor e docente na área de Design no SENAI-DF de 1989 a 2012. Sócio idealizador do Instituto de MetaArteDesign - IMAD. moluap.artes@gmail.com
} 
RESUMEN: En este artículo se socializa parte de los resultados de una investigación práctica en la formación docente transdisciplinario para la Formación Profesional. En particular, reducir el uso de Estrategia Pedagógica - Praxis Dialogic Artes, articulando guiar Transdisciplinario Enseñanza y supuestos metodológicos para el desarrollo de Competências Profesionales. El principal objetivo de esta reflexión fue verificar la eficacia de esta estrategia para la formación del sujeto cognoscente en las dimensiones de la vida a la vida. Corazón Investigative rompió respuesta a la hipótesis: ¿Qué tan efectiva es la estrategia de enseñanza de la praxis dialógica artística aplicada a la formación integral del ser humano? Estudio para Curso Interdisciplinario de Formación del Profesorado, para la enseñanza en diversos cursos de formación profesional, en particular en las áreas de diseño, comunicación y artes visuales, ofrecidos por las instituciones en el Distrito Federal y sus alrededores. La investigaciónacción concebida y en base a las interconexiones del pensamiento complejo (Edgar Morin); enfoque transdisciplinario para la educación de los ecosistemas (María Cándida Moraes, Humberto Maturana y Patrick Paul); la pedagogía del diálogo (Paulo Freire); los principios de la educación del siglo XXI, aboradados en la UNESCO informa, para el proceso de aprendizaje y que se refieren al conocimiento: aprender a aprender, aprender a hacer, aprender a vivir juntos y aprender a ser (Jacques Delors); entre otros estudios científicos colaborativos. Esta estrategia es la praxis pedagógica transdisciplinario más eficaz, que busca promover el conocimiento del "entrenamiento cruzado" del alumno sujeto, junto con los conocimientos técnicos y científicos, técnicos y habilidades sociales, organizativos y metodológicos. Por lo tanto, el conocimiento de colaboración para hacer frente a la incertidumbre y asegurar la perpetuación de un mundo complejo - interconectados y lleno de paradojas.

Palabras clave: Estrategia de la Enseñanza Artística. Formación del Profesorado. La enseñanza de competências. Educación Profesional. La enseñanza interdisciplinaria.

\begin{abstract}
This article socializes part of results of practical research in teacher education to Professional transdisciplinary education. In particular, cut the use of Pedagogical Strategy Praxis Dialogic Arts, articulating guiding Transdisciplinary Teaching and methodological assumptions for the development of Professional Competences. The main objective of this reflection was to verify the effectiveness of this strategy to the formation of the knowing subject in the dimensions of life to life. Investigative heart broke response to the hypothesis: How effective is the teaching strategy of Dialogic Praxis Artistic applied to the integral formation of the human being? Study for Interdisciplinary Teacher Training Course, for teaching in various professional courses, particularly in the areas of design, communication and visual arts, offered by institutions in the Federal District and surrounding areas. Action research conceived and based on the interconnections of complex thinking (Edgar Morin); transdisciplinary approach to ecosystem education (Maria Candida Moraes, Humberto Maturana and Patrick Paul); the pedagogy of dialogue (Paulo Freire), the principles of the XXI century Education, aboradados in UNESCO reports, to the learning process and that refer to knowledge: learning to learn, learning to do, learning to live together and learning to be (Jacques Delors); among other collaborative scientific studies. This strategy is more effective transdisciplinary pedagogical praxis, which seeks to promote awareness of the "crosstraining" of the subject learner, in conjunction with the technical and scientific, technical skills and social, organizational and methodological skills. Therefore, collaborative knowledge to face uncertainty and ensure the perpetuation of a complex world interconnected and full of paradoxes.
\end{abstract}

Keywords: Artistic Teaching Strategy. Teacher Training. Teaching Competences. Professional Education. Interdisciplinary teaching. 
"Uma estratégia é a atuação sequenciada potencialmente consciente do profissional em educação, guiada por um ou mais princípios da Didática e encaminhada à otimização do processo de ensino-aprendizagem."

Núria Rajadell (2012)

\section{1 - INTRODUÇÃ̃ - Vida e Educação}

Inegáveis são as vantagens, ao entendimento do nosso mundo, da paulatina fragmentação das disciplinas, bem como, a criação de subdisciplinas, que firmou nas últimas décadas do século XIX e persiste até os dias atuais, em que, o Ocidente europeu, consolida a estruturação do conhecimento em grandes modelos do seu pensamento: mitológico, filosófico, teológico e científico. Para Morin (1999), tal geração de saberes foram edificados sobre os pilares da ordem, da separatividade, da razão e da desconsideração da subjetividade, caracterizando a atual supremacia da moderna ciência sobre o ser, com oportunização de intensificadas desvantagens às espécies, ao planeta, com drásticas mazelas aos interligados ecossistemas.

Deste modo, evoluímos em percalços e chegamos aos tempos hodiernos alarmados, principalmente, com o surgir cotidiano de revolucionárias tecnologias que, na sua maioria, são geradoras de vicissitudes generalizadas, degradativas do ser humano. Por meio da valorização de uma cultura depreciativa dos valores éticos, que privilegia a competição, a dominação, o egoísmo, o desamor, a desconfiança, a ganância entre outras. Decididamente, são agregativas instabilidades, predatórias da vida, percebidas em todas as magnitudes interrelacionais.

Felizmente intensifica-se no cenário educacional inquietações, questionamentos e debates sobre novas práticas pedagógicas, propondo soluções educativas às concepções ainda vigentes: mecanicistas, ditatoriais, assistencialistas, bancárias entre outras que não mais atendem ao novo mundo posto. São abrangentes investigações que aprofundam reflexões integrativas das epistemológicas, metodológicas e ontológicas, tendo como linha condutora a articulação dialógica entre a vida e a educação. Deste modo, buscamos consonância de ideias e ações, com oportunos exercícios a partir do discenso, ou seja, na democrática prática do diálogo isonômico - direito a saber ouvir, falar e ser ouvido - resgatamos termos, consolidamos conceitos e suscitamos o insurgir de novas terminologias intercolaborativas.

Nos embates às desafiadoras realidades, surgem ensejos para implementar significativas 
mudanças educacionais, que inicia por uma conscientização humana no aproveitamento de todos os indivíduos colaborativos ao coletivo, bem como, esforços de todas as estruturas sociais em serem facilitadoras, democráticas e inclusivas dos indivíduos no conviver social. Transformações que requerem do mundo desvalorizado da educação, interconexão dos pressupostos da Teoria do Pensamento Complexo, nas abordagens Didáticas Transdisciplinares e outros avanços didáticos, unificando saberes integrativos e colaborativos aos processos de ensino e aprendizagem.

[...] este momento revela-se de grande e extrema oportunidade para se catalisar mudanças educacionais importantes, transformar a maneira como pensamos e concebermos a escola, a educação e a própria vida. (MORAES, 2003, p. 167).

Segundo Maturana (2008) a busca às soluções dos problemas humanos, na nossa historicidade, nunca foi de total domínio de novos conhecimentos científicos e de inovadoras tecnologias, mas sim, pelos principais propulsores da vida, que são os desejos, os sonhos e as emoções dos seres. Nesta pespectiva, alguns otimistas quanto ao evoluir humano, percebem sinais de que nossos limites são superáveis, quando motivados e regidos, primeiramente, por nossas emoções. Portanto, oportunizadoras de uma nova consciência paradigmática no nosso modo de viver integral e integrado, tornando-nos responsáveis pelas nossas ações na construção de uma nova realidade com atitudes sócio-afetivas, colaborativas, amorosas, respeitosas, tolerantes nas diferenças humanas, impregnadas de valores éticos, de compaixão, para um eterno emocionar no viver, irmanados para o bem-viver físico e espiritual de todos.

Neste contexto, a atenta práxis docência interligadora da vida e educação, oportunizou o emergir da estratégia didática transdisciplinar que religa diferentes enfoques, com aplicação da práxis dialógica artística, buscando criativas formas mais eficazes nas ações educativas. Ambição de evidenciar competências profissionais nos alunos e "trans-formação" na e para a vida. Resposta também, após participações frustradas em variados cursos de capacitação docente à Educação Profissional. Programas formatados com emaranhados de notórios saberes mas, na sua maioria, apresentados como "aulas-show", sem contexto com vivências em docência, portanto, sem significação. Afinal, aprendemos em anos de práxis docente, empírico pensar complexo e abordagens pedagógicas transdisciplinares, em articulação com a teoria exemplificada na prática e contextualizada nas coisas do mundo, oportuniza um expressivo apreender transformador - segurar com as mãos e, porque não dizer, também com o coração.

Para o propósito desse estudo, tem-se a fundamentação no pensamento sistêmico, a fim de se almejar reflexões sobre as possibilidades de uma didática transdisciplinar constituir-se 
colaborativa a "trans-formação" integral e integrado do ser humano. Assim, aqui socializamos, umas das estratégias pedagógicas oportunizada na Formação Docente Transdisciplinar à Educação Profissional, para professores atuantes em cursos nas áreas de design, comunicação e artes visuais, ofertados por instituições no Distrito Federal e entorno. Fundamentada na práxis educacional dialógica amorosa e acolhedora em todos os processos de ensino e de aprendizagem. Valorativa dos desejos, dos sonhos, das emoções, que resgata o sujeito colaborativo à "trans-formação" do "ser-consciente-ético" para com o todo planetário.

\section{2 - DIÁLOGOS TRASDISCIPLINARES PARA UMA NOVA EDUCAÇÃO DESAFIOS DA PRÁTICA DOCENTE À EDUCAÇÃO POR COMPETÊNCIAS}

No Brasil, na história em curso, registra-se uma difícil realidade geral da educação, que nos cumpre resolver, integrando saberes (sociais, econômicos, políticos, espirituais), que afetam e são constitutivos da vida. Igualmente preocupante é a crise da Educação Profissional, que segundo o documento norteador nacional da Metodologia SENAI de Educação Profissional (2013), a Educação Profissional, desde sua implantação no Brasil, molda-se na realidade socioeconômica vigente. Nas décadas de 1950 e de 1960, o modelo tayloristafordista prevaleceu no mundo do trabalho, em que se legitimou a dicotomia entre quem concebe e quem executa um produto (bens ou serviços), cabendo à Educação Profissional valorizar habilidades manuais desenvolvidas por uma dinâmica de treinamento repetitivo. Na década 1970, apresentava-se nova organização mundial com evoluções tecnológicas e radicais mudanças na dinâmica social, impondo maior qualidade dos produtos para uma necessária competitividade econômica. O modelo de trabalho migrou para o modelo de produção flexível, denominado toyotista, cabendo aos trabalhadores a capacidade de iniciativa e tomada de decisões e de assumir responsabilidades. E, sem grandes avanços passamos pela década de 1980, enfrentando estagnação econômica e busca por soluções para um mundo em globalização - produções indústrias colaborativas em redes. Assim, ganha força a competitividade das empresas, emergindo o fator competências humanas com relevância na organização produtiva e, assim, chegamos nos anos de 1990, enfatizando o conceito de Ensino por Competências.

O termo Competências foi amplamente difundido por vários estudiosos da educação, principalmente, após contribuições da divulgação do relatório encomendado pela UNESCO à Comissão Internacional sobre Educação para o século XXI, criado pela UNESCO sob a presidência de Jacques Delors (1998), que pontuou alguns princípios para o processo de 
aprendizagem quanto aos saberes: aprender a aprender; aprender a fazer; aprender a conviver e aprender a ser. Pontuados como saberes essenciais requeridos pelo mundo do trabalho para o desenvolvimento de Competências e para uma formação integral do indivíduo.

A vigente legislação educacional no Brasil, a Lei 9.394/96 de Diretrizes e Base da Educação Nacional e o conjunto da legislação complementar de regulamentação, o Decreto Lei 2.208/97 e as Diretrizes Curriculares Nacionais para Educação Profissional, consubstanciadas no Parecer 16/99 que lhe deram sequência, baseados na flexibilidade e racionalização, assume como concepção orientadora o modelo de competências, claro, atendendo primeiramente o setor produtivo. Entretanto, existem diversas definições do que é competência. Em síntese, remetem a uma mesma ideia conceitual, salvo ênfases ideológicas ou interesses investigativos. Neste texto, aqui, compreende-se o termo competências como a aptidão do indivíduo em articular saberes de: fundamentos técnicos científicos conhecimentos; capacidades técnicas - habilidades; e capacidades sociais organizativas e metodológicas - atitudes; atendendo situações nas dimensões de caráter pessoal, profissional ou social.

Percebe-se assim, uma limitada interpretação do conceito de formação integral e integrado. Somente pela ótica interdisciplinar e multidisciplinar para o desenvolvimento de Competências, buscando relevância produtiva e competitiva mercadológica. Portanto, com parca abrangência da totalidade do ser integrado ao todo constitutivo, ou seja, sem ligações propositivas da abordagem transdisciplinar - concebida como ciência das ligações entre disciplinas acadêmicas e não acadêmicas para resolução de problemas complexos, por método das interações entre saberes disciplinares e saberes vitais. Podemos notar que existem abertura aproximativas entre ensino por competências e abordagem didática transdisciplinar à educação. Além dos princípios pontuados por Delors, em destaque, do aprender a ser e a conviver, ainda destacamos a afetividade, o diálogo, a colaboração para a construção coletiva do conhecimento.

Este novo paradigma exige, também, novas competências do docente, sendo um líder orientador de grupos, mediando processos significativos de aprendizagens e não mais um mero "repassador" de conhecimentos, ou seja, um repetidor de práticas profissionais rotineiras. Agora, além dos conhecimentos específicos, requer-se do docente competências em variadas estratégias pedagógicos e abrangências culturais em diálogos. Como assegura Moraes: emergência do conhecimento interdisciplinar. Interação entre especialistas 
disciplinares, entre pessoas envolvidas e o estabelecimento de um diálogo entre todos, um diálogo que viabiliza a elaboração de um projeto comum capaz de colaborar para a superação da fragmentação do processo pedagógico e do conhecimento nele trabalhado. (MORAES, 2008, p. 115).

\section{PRÁXIS DOS DIÁLOGOS E ESTRATÉGIAS PEDAGÓGICAS}

Para Freire (1987, p. 38), “A práxis é reflexão e ação dos homens sobre o mundo para transformá-lo". Portanto, um tipo de diálogo entre o sujeito, sua ação e resultado do objeto produzido. Então, um dos recursos estratégicos educacionais que são utilizados, visando conseguir aproximação entre professor e alunos, interagindo de forma mais assertivas nos processos de ensino-aprendizagem. Correlacionadas com o desafio proposto, permite-se ao docente facilitar o desenvolvimento do aprendizado do aluno, bem como a construção de laço de confiança e respeito entre todos. Igualmente, permite-se ao professor entrar em contato com os níveis de realidades de cada aluno para diversificar estratégias quando necessário. Portanto, lembra Rajadell (2012, p. 105) "não podemos esquecer a importância das estratégias didáticas como coluna vertebral de qualquer ação formativa.". Assim, entendemos que os diversos tipos de diálogos, na perspectiva das interações educativas, assumem o papel de um tipo de energia transversal, integrativa e propulsora das estratégias pedagógicas de ensino.

Pontua Paulo Freire (2000), que ensinar não é transferir conhecimento, mas criar as possibilidades para a sua própria produção ou a sua construção. Estes são desafios que procura estabelecer uma situação onde o aluno possa exercitar suas habilidades de estudar e agir com iniciativa, autonomia, consciência política e responsabilidade ética entre outras, além da ação prática transformadora decorrente de tudo o que pode ter aprendido. Portanto, as estratégias pedagógicas são instrumentos que facilitam a efetivação das competências explicitadas no currículo. Oportunizadoras de interações do aluno com a construção do seu progresso cognitivo. Isto é, saber fazer e analisar criticamente o que está sendo feito.

\section{PENSAMENTO COMPLEXO E DIALOCIDADE NA EDUCAÇÃO}

São precursoras e colaborativas ao Pensamento Complexo, a teoria do grego Euclides de Alexandria, que viveu por volta dos anos 300 a.C. O matemático teorizou que para que um todo, dividido em partes desiguais, pareça harmonioso, é preciso que exista, entre a parte pequena e a maior, a mesma relação que entre a maior e o todo (RIBEIRO, 1998). Por sua vez, Marcus Vitruvius Pollio, no século I a.C., colaborou com essa teoria com a introdução da Proporção Áurea, ou Relação Áurea. O tratado deixado pelo arquiteto romano, registrado na sua obra de 10 volumes "De Architectura", contribuiu para as ciências com a teoria sobre proporção e simetria para uma melhor harmonização relacional entre às partes constitutivas de 
um todo.

No século XVII, época de primazia da razão, o pesquisador científico em física e matemática Blaise Pascal (2001) enveredou por outros caminhos e colocou o ser humano como o centro da investigação filosófica. Sem negar a razão, afirmou conhecermos a verdade não apenas pela razão, mas também pelo coração, ou seja, ele observa que a razão tem limites e que a mesma, quando tenta lidar com o emocional ou religiosidade, fica quase sem nenhuma valia. Na sua obra Pensamentos, afirma: “O último passo da razão é reconhecer que há uma infinidade de coisas que a ultrapassam". (PASCAL, 2001, p. 188). Registra-se, ainda, na sua obra:

Sendo todas as coisas causadas e causantes, ajudadas e ajudantes, mediatas e imediatas, e todas se mantendo por um laço natural e insensível que liga as mais afastadas e as mais diferentes, tenho como impossível conhecer as partes sem conhecer o todo, assim como conhecer o todo sem conhecer particularmente as partes. (PASCAL, 2001, p. 199).

Tais teorias parecem ser a base fundamental das contribuições do Pensamento Complexo de Morin (1999). Para o autor um Pensar Complexo é o maior desafio na hodiernidade, pois requer uma reforma do modo de pensar. O paradigma vigente foi constituído pela ciência clássica, edificada sobre três pilares: primeiro, a noção de ordem determinista, sendo a desordem fruto da ignorância; segundo, a noção de separatividade cartesiana, que defende o estudo de um fenômeno, decompondo-o em sua simplificação e especialização, até chegar a hiperespecialização disciplinar, sem considerar o sujeito observador; e terceiro, razão absoluta, que por sua vez reposa três princípios (da indução, da dedução e da rejeição da contradição).

Morin (2000, p. 204 e 205) instiga ao pensamento complexo, sem abandono dessa lógica clássica da ciência, mas a uma combinação dialógica transgressiva com os segmentos onde a ciência para de ser operacional. Portanto, o autor fundamenta seu pensamento em princípios em respostas aos desafios contemporâneos, os quais sintetizamos os de mais relevância à estratégia dialógica. São eles, os Princípios: Dialógico, propositivo da união das noções antagônicas "para pensar os processos organizadores, produtivos e criadores no mundo complexoa da vida e da história humana"; da Recursão organizacional, que "ultrapassa a noção de regulação para aquele de autoprodução e auto-organização..., os indivíduos humanos produzem a sociedade em e mediante as suas interações, mas a sociedade, enquanto um todo emergente, produz a humanidade desses indivíduos trazendolhes a linguagem e a cultura"; e Hologramático, que se aplica tanto à compreensão dos fenômenos biológicos, físicos e sociais, "nos quais não somente a parte está no todo, mas o 
todo está na parte”. Então, o indivíduo é parte da sociedade, que está presente em cada indivíduo, por meio da sua linguagens, culturas, normas.

Segundo Morin (2008), “complexus", em latin, significa "o que rodeia”, "o que inclui". Seu particípio, na mesma língua é "complecti”, que significa "rodear", “abraçar". O prefixo “com", significa "junto". Juntando com o sufixo, também em latim, "plectere", forma a palavra "complectere", formadora do termo complexo, ou seja, tecer junto, em conjunto, e ao mesmo tempo, entrelaçar, estar e fazer em rede. Para o autor, complexidade é "aquilo que é tecido junto". Na palavra "aquilo", subentende-se certezas, emergências, contrários das certezas, o mundo ecossistêmico, agregação complementar para interligar.

Portanto, na epistemologia da complexidade nortea-se religação e completude do ser, que nega a simplificação, a aceitação das ambiguidades, das diversidades, do reconhecimento da condição ecossistêmica, interacionista e transdisciplinar das diversas realidades da parte e do todo, do sujeito e do objeto, do ser e do cosmo.

\section{ABORDAGEM DIDÁTICA TRANSDISCIPLINAR E PRÁXIS DIALÓGICA}

Pensemos: se essas teorias comprovam a relação harmoniosa entre as partes com o todo nas artes, na arquitetura, na biologia, então, por que não trazê-las à luz das emergências da educação? A proposta epistemológica sobre Complexidade de Morin (2008) é um norteador para uma nova consciência educacional integrativa do homem à sua natureza. Do homem visto como parte de um todo. Neste enfoque, não podemos conceber um todo sem uma parte e muito menos isolar a parte de um todo. Concernente a formação plena do ser humano, primeiramente temos de reconhecer sua multidimensionalidade - cósmico, ecológico, econômico, espiritual, histórico, místico, político e social. Na dimensão prática, Maturana (2008) nos lembra que: "a educação é um processo de transformação na convivência, em que o aprendiz se transforma junto com os professores e com os demais companheiros...". Então, não podemos conceber uma educação sem diálogo entre sociedade e sua parte constitutiva - o homem. Contribuitiva ao enfoque, define Moraes o novo "Educar emergente", como:

(...) um fenômeno biológico fundamental que envolve todas as dimensões do viver humano, em total integração do corpo com a mente e com o espírito, lembrando que, quando isto não ocorre, produzem-se a alienação e a perda do sentido social e individual no viver/conviver. Educar é enriquecer a capacidade de ação e de reflexão do ser aprendente; é desenvolver-se em parceria com outros seres. (MORAES, 2010, p. 41).

Assim, paulatinamente, emerge uma epistemologia transdisciplinar e suas propostas metodológicas à educação. Que tem clareza que o reducionísmo científico e suas respectivas metodologias não respondem de forma plena aos problemas do mundo contemporâneo. 
Reforça Patrick Paul (2013), que "a busca de ligações entre diferentes enfoques faz parte da abordagem transdisciplinar". O autor entende a transdisciplinaridade, nos enfoques, como:

[...] ciência das ligações, das interfaces, das pontes e dos cruzamentos entre disciplinas acadêmicas. [...] método de resolução de problemas complexos, envolvendo as interações entre conhecimentos disciplinares e saberes vitais, que também se revelam como fontes de informações, formação e transformações. (PAUL, 2013, p. 11).

Portanto, a prática educacional transdisciplinar é uma nova maneira de pensar, sentir e perceber os diversos níveis de realidades que se interrelacionam na e à vida. Em outras palavras, entende Nicolescu (2002) a transdisciplinaridade no que está entre, através e além das disciplinas e, ao considerar tais pressupostos de forma interativa e relacional. Sua prática caracteriza-se pela liberdade e direitos humanos, respeito, convivência, conservação dos meios naturais, melhoria das condições de vida, consumo consciente e, bem estar individual, social, planetário. Em estudo colaborativo, a pesquisadora educacional Arnt (2010, p. 111) define didática transdisciplinar no livro Complexidade e Transdisciplinaridade em Educação, como: "um método iterativo, de aproximações sucessivas por meio da pesquisa, da experiência, resinificando resultados, retornando sempre ao propósito e à intencionalidade da própria ação". Complementa seu entendimento, num enfoque mais prático, quanto:

[...] uma postura perante o conhecimento, indo além da disciplina, articulando Ciências, Artes, Filosofia e Tradições, reconhecendo a multidimensionalidade humana e os múltiplos níveis de realidade, permitindo ao ser a interconexão com a natureza, com o outro, consigo mesmo, alicerçando a ética, ampliando as suas potencialidades humanas, na busca do bem comum. (ARNT, 2010, p. 111).

\section{ABORDAGEM DIÁLOGICA NA PRÁXIS EDUCACIONAL}

A palavra "Diálogo", etimologicamente é a fusão dos termos gregos "dia" que significa "através" e "logos" que foi primeiramente traduzido para o latim como "ratio" que significa "razão"; mas "logos", na sua acepção mais antiga é entendida como "relação", "relacionamento". Portanto, o Diálogo é uma forma de significar e circular sentidos, palavras, expressões. Na sua prática básica a intencionalidade de integrar em vez de decompor, buscando fortalecer vínculos e criar redes, que identifica, explicita e compreende às dificuldades relacionais. Enfim, na prática processual do Diálogo podemos identificar princípios, questionar ideias e cristalizar posições, para isso, apoiando-se nos nossos valores éticos, julgamentos, preferências e ações.

Por sua vez, a palavra "Práxis" tem origem grega e diz respeito à "prática". Faz alusão ao processo pelo qual uma teoria passa a fazer parte da experiência vivida. Na proposta pedagógica de Freire (1987, p.38), “A práxis é reflexão e ação dos homens sobre o mundo para transformá-lo.”. Portanto, a Práxis é também um tipo de diálogo reflexivo do sujeito 
sobre suas ações projetadas, com recursividade consciente para a atividade humana em sociedade e na natureza.

Entendemos, neste texto, aplicada em específico na estratégia pedagógica, a práxis caracteriza-se processual, onde um fundamento técnico e científico, uma capacidade técnica, uma capacidade social, organizativa e metodológica, se converte em uma competência e em uma experiência vivida com retroalimentação, transformando a natureza e, por conseguinte, transformando a si mesmo. Um processo cíclico de ensino aprendizagem de contemplação reflexiva das teorias aplicadas à prática que ligam-se com a realidade vivenciada. Assim, a práxis é uma relevante etapa à construção de conhecimento, experimentando abstratas teorias no mundo físico em contínuo contemplação reflexiva dos resultados.

O diálogo tem uma significação polissêmica, pode denotar processo de estudo, da reflexão, da explicação, da prática que leva ao conhecimento. Suas possibilidades de entendimento pelo discurso quanto pela racionalidade, identificação tanto pela palavra e pelo pensamento e, pela conversação como pela ação. Reconhece-lhe interação essencial na historicidade à condição do desenvolvimento humano, nas dimensões epistemológicas, metodológicas e ontológicas. Freire entendia o diálogo como "exigência existencial". Para o educador, o diálogo manifestava-se quando fundamentado na humildade - onde os homens recriam o mundo permantemente, sem arrogância; no amor - entendido, também, como um ato de coragem e de compromisso para com os outros seres; na fé intensa nos homens; na esperança - que reconhece a imperfeição dos homens, motivando-os a uma busca eterna; e no pensar que possibilita a construção do conhecimento e da cultura. (FREIRE, 1987, p. 79 a 82).

Portanto, é relevante entender o ser humano nas dimensões do pensar, sentir e agir, contributivas para a formação integral e integrado do ser humano. Uma abordagem capaz de uma sinergia social ética e justa percebida, fortemente, no pensamento educacional de Freire (1998), sugerindo que o conhecimento passa pelo corpo, pela razão e pelos sentimentos compreensão da educação integral do ser. Para isso, devemos utilizar uma didática fundamentada na dinâmica do diálogo em articulação com outras possibilidades facilitadoras nos processos de ensino aprendizagem. Sendo o eixo norteador o diálogo, mediados intencionalmente, caracterizados em momentos como dialético, dialógico e dialogicidade, objetivando um caminho educativo eficaz. 


\section{3 - MÉTODOS DA ESTRATÉGIA PEDAGógICA DIALÓGICA ARTíSTICA}

Notadamente, existem convergências e complementariedade entre os referenciais teóricos, principalmente, tendo como ponto comum o diálogo nos processos de ensino aprendizagem e suas variadas possibilidades. O que inspirou e referenda a pergunta orientadora do problema investigativo - Qual a eficácia da utilização da Estratégia Pedagógica da práxis dialógica artística na capacitação de docentes à educação profissional e, também em colaboração à formação integral e integrada do ser? Portanto, recomenda-se o estudo, na fonte, dos referidos fundamentos teóricos. Por serem inspiradores à nova educação, bem como, relevantes para delimitação da estratégia pedagógica aqui apresentada. Resposta prática com articulação de saberes, entre outras possibilidades, às Diretrizes da LDB (Lei 9.394/96; Decreto Lei 2.208/97; Parecer 16/99) propositivo de ensino por competências e aos princípios fundamentais recomendados por Delors à educação no século XXI:

[...] deve organizar-se em torno de quatro aprendizagens fundamentais que, ao longo de toda a vida, serão de algum modo para cada indivíduo os pilares do conhecimento: aprender a conhecer, isto é, adquirir os instrumentos da compreensão; aprender a fazer, para poder agir sobre o meio envolvente; aprender a viver juntos, a fim de participar e cooperar com os outros em todas as atividades humanas; finalmente, aprender a ser, via essencial que integra as três precedentes. (DELORS, 1998, p. 89-90).

Então, objetivou-se, no referido recorte investicativo: Verificar a eficácia da estratégia pedagógica da práxis dialógica, evidenciada por meio de práxis artística colaborativa, respaldados por pressupostos didáticos transdisciplinares e princípios metodológicos para o desenvolvimento de Competências, oportunizando construção de competências (conhecimentos, habilidades e atitudes), bem como, a inteireza do ser consciente, integrado na e à vida.

A investigação é pertinente à formação docente, em particular, na docência em Educação Profissional. Colaborativa para a formação pedagógica dos competentes técnicos, os quais, na sua maioria não possuem licenciatura. Então, daí dificuldades para transpor teorias pedagógicas em práticas didáticas nos processos de ensino e aprendizagem. A maioria dos programas de capacitações de carentes docentes profissionalizantes, limitam-se a palestras, ou rápidos encontros. Conduzidos por educadores renomados, apresentadores de "aulas-show" de significativas teorias. Mas, sem tempo para propor significação prática à 
teoria. Enfim, sem consolidação em ação prática exemplificativa. Total desconsideração da observação de Trigueiro (2000), “a ação humana encontra-se consigo mesma, capacitando-se o homem todo para a totalidade da ação." Portanto, importância da plenitude do diálogo entre as dimensões do homo sapiens (que conhece a realidade e tem consciência do mundo e de si, de pensar), com o homo faber (que é capaz de fabricar com referências, de agir).

\section{PERCURSO METODOLÓGICO}

Informações iniciais relevantes - Durante a realização da investigação, a postura do docente foi de mediador e facilitador do desenvolvimento da aprendizagem: incentivou a socialização dos conhecimentos prêvios de leitura e vivência de mundo; introduziou a Situação-problema, subdividido em contexto do panorâma mundial; e propôs desafio investigativo da eficácia da estratégia do diálogo à educação. Tal atitude docente motivou e significou a aprendizagem dos alunos-docentes. Conscientes da importância do estudo autorizaram os registros de evidências e, bem como, publicação em artigo científico.

A proposta inicial do desafio, pelo investigador, era para desenvolver uma pintura coletiva sobre tela de forma dialógica e colaborativa. Na aberura do planejamento, acolheu-se a ideia de um dos alunos-docentes na realização de duas obras de artes para fins comparativos. Sendo, a primeira realizada sem diálogo entre os protagonistas e a outra, conforme a sugestão do docente, com ampla colaboração e mediação dialogal. Sugestão acatada por todos e, de imediato, voltamos ao planejamento e atualizamos os registramos orientadores à Competência e práxis investigativa. Então, acordos feitos entre os membros, rumamos para o preparativo dos recursos necessários - encomenda de duas telas, cada uma, no formato 100 x 120 centímetros, bem como, preparação de resenha do referencial teórico a ser utilizado antes do Desafio 2, para revisita aos fundamentos epistemológicos, metodológicos e ontológicos, aqui já pontuados. É importante frisar que, durante o recorte investicativo, os docentes já tinham participado de grande parte da carga horária do programa para Formação Docente Transdisciplinar à Educação Profissional.

Procedimentos metodológicos - Caracterizou-se como uma pesquisa prática - PesquisaAção, baseada na reflexão de uma práxis educacional sem perder de vista o rigor metodológico. Foi uma investigação qualitativa, semiestruturada concomitante à análise documental. Dinâmica e interativa, ela retroalimentou-se, reformulou-se constantemente com a participação do sujeito no fazer científico. Portanto, integrou teoria a prática por meio da coprodução de conhecimentos entre os participantes e o pesquisador por meio de processos 
comunicativos e colaborativos entre os protagonistas. Na coleta de dados foi utilizada a técnica fotoetnográfica - registro fotográfico, entrevista e registro de fatos relevantes ocorridos durante o Programa de Formação Docentes.

Universo, Local e Período de Realização da Pesquisa - Aplicada na Formação em Docência Transdisciplinar à Educação Profissional, ainda em curso. Sendo conduzida pelo autor do artigo. O qual também participou das práxis investigativas juntamente com 6 discentes. Destes, 3 docentes atuantes e outros 3 futuros docentes. Todos igualitários em capacitação pedagógica, para atuação como instrutores na Educação Profissional. Em cursos variados nas áreas de Comunicação Visual gráfica e editorial, Design de Interiores, Artes Plásticas e Artes Artesanais.

O programa de formação, em curso, e as investigações acontecem nas dependencias do futuro Instituto de Meta-ArteDesign - IMAD, no Distrito Federal. Capacitação iniciada no ano de 2014 e com o término previsto para o findar do ano de 2015. Caracteriza-se como uma vivência práxis em artes e ao mesmo tempo como uma formação continuada em didáticas de ensino, integrando alunos, atuantes docentes e aspirantes docentes. Os encontros são realizados uma vez por semana, nas tardes dos sábados. Aconteceram no último sábado de janeiro de 2015 e nos dois sábados subsequêntes do mês de fevereiro de 2015.

Movimentos Iniciais Dialógicos à Competências - Propositivo pelo autor deste artigo, mediados e com abertura dialógica. Assim realizados, na ordem:

- Contextualização - introdução da justificativa de mudança paradigmática na educação vigente, iniciando por revisita aos marcos históricos educacionais;

- Mediação para Contribuições Prévias dos alunos, oportunizadoras da socialização de diferentes níveis de realidades, significando importância à competência;

- Abertura do Planejamento das aulas para o desenvolvimento da práxis e da investigação, significando e motivando o aluno. Redireciona rumos do planejado, por meio de estímulos de ideias e negociações democráticas;

- Reflexão da competência, objetivando visualizar o perfil profissional docente esperado, bem como aceitação sensível da investigar a eficácia da Estratégia Pedagógica em Práxis Dialógica Artística. A competência foi redigida referendada na experiência do autor deste artigo, como consultor-externo na elaboração da Metodologia SENAI de Educação Profissional (2013), o qual propõe a seguinte estrutura: Realizar (verbo de ação no infinito) + pintura coletiva sobre tela, (descrição do objeto/produto - bens ou serviços) + objetivando investigar a eficácia da Práxis da Estratégia Pedagógica Dialógica, por meio de realização artística, + que evidencie uma formação integral e integrado do ser (elemento de competência + padrão de desempenho);

- Proposição do Desafio pelo docente-facilitador, com estímulos às contribuições dos 
discentes-docentes;

- Potuações dos Recursos Necessários à realização do desafio artístico;

- Negociações dos Prazos à execução do desafio;

- Negociação da Verificação da Aprendizagem, propondo sistemática, critérios e parâmetros à verificação da aprendizagem;

- Apropriação da Verificação, com diálogo sobre os resultados e, propor transposição dos conhecimentos, habilidades e atitudes para outras competências necessárias na vida, bem como, adaptando para outras situações nos processos de ensino-aprendizagem.

Desenvolvimento do Desafio 1 - SEM diálogo - Contando apenas com diálogos com seus saberes internos os investigados pintaram uma mesma obra. Por último, contribuiu o docente orientador da investigação, para não induzir com sua ação artística. O planejamento, sempre em mãos, foi importante para dispor os materiais necessários para a pintura e, lembrar das negociações de convivência e dos prazos estabelecidos para finalização, ou seja, três horas para realização coletiva da obra artística.

A seguir, apresentamos seleção de duas fotos, evidenciando o momento inicial e final.

Figura 1 - Dois momentos da prática Artística do Desafio 1 - SEM diálogo
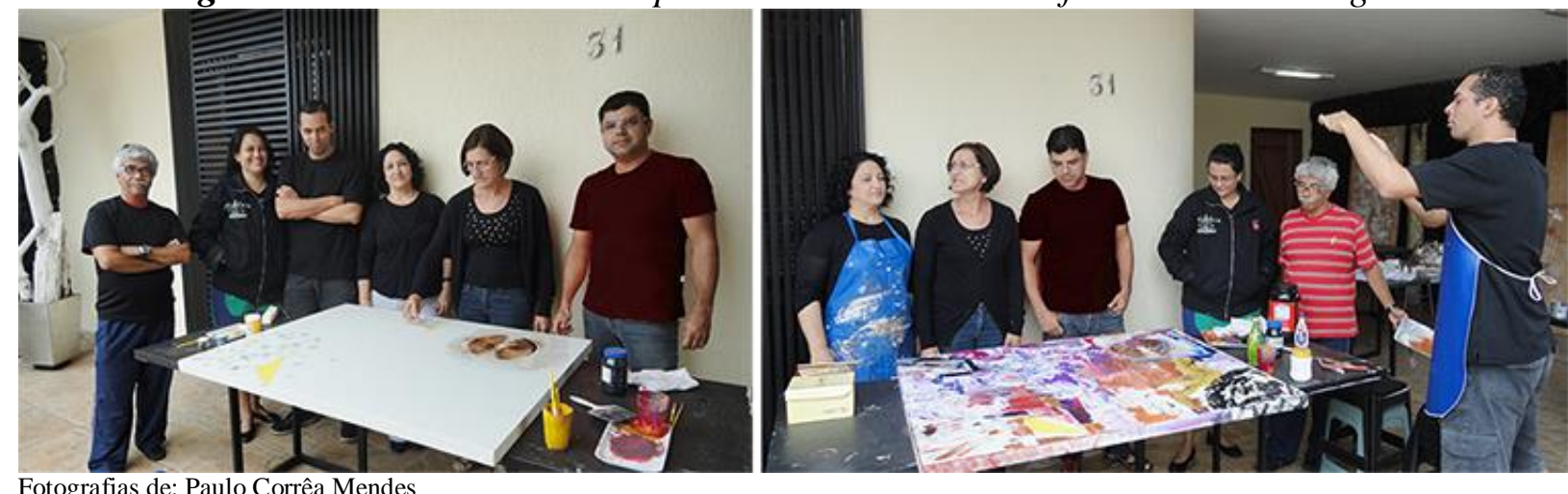

Fotografias de: Paulo Corrêa Mendes

Nos últimos 20 minutos do encontro, o docente-orientador incentivou a troca a distância de informações em geral entre os protagonistas e aproveitou para comunicar que seria enviado por e-mail copilações de pontos relevantes dos aportes teóricos já estudado pelo grupo, objetivando reforço epistemológico, metodológico e ontológico para o desenvolvimento do próximo desafio. Reforçou, ainda, atitude de total abertura e incentivo aos diferentes tipos de diálogos qualitativos, buscando informações de experiência de vida para a construção da aprendizagem do outro. Por fim, destacou a importância da presença de todos no próximo encontro.

Desenvolvimento do Desafio 2 - COM dialogicidade - O Desafio 2 foi efetuado, também, numa tarde de um sábado. Intervalo de dias que foi relevante para leitura e reflexão do 
referencial teórico. Tal qual neste texto é apresentado, foi enviado aos participantes após término do Desafio 1. Assim, os docentes em capacitação pedagógica puderam revisitar e reforçar os pressupostos à nova educação. Principalmente, da linha condutora do diálogo de Freire, na sua proposta pedagógica ética, igualitária e libertadora à educação transformadora; da teoria do pensamento complexo de Morin, para uma educação consciente; ressonantes e colaborativos à prática transdisciplinar educacionais; e em princípios para o desenvolvimento de Competências.

Os Movimentos do Desafio 2, deram-se na ordem de realização:

- Dez minutos de Meditação, que foi conduzida pelo docente-facilitador e com auxílio de escuta de uma música apropriada;

- Após a meditação, solicitou-se que os membros do grupo fizessem Recorrência “diálogo interno" com seus saberes, necessários à realização da pintura coletiva;

- O planejamento em mãos foi importante para relebrar o Acordo de Convivência entre os protagonistas, bem como, frisar desenvolvimento da práxis COM diálogos colaborativos e atenção reflexiva, sem perder o foco no propósito;

- Após Mediação docente, a timidez do grupo foi quebrada. Um dos membros sugeriu a necessidade de uma linha criativa para melhor resultado harmônico. Todos os envolvidos contribuíram com sugestões e negociaram o uso de cores, técnicas, formas estéticas e geométricas e, linguagem temática para ser explorada;

- Durante cada etapa de realização da pintura, os membros trocaram bastantes informações e impressões. Diálogos Qualitativos orientadores ao melhor caminho individual a seguir, com total liberdade de livre-arbítreo;

- Devido o total envolvimento, a intervenção mediadora do docente-orientador ocorreu em alguns momentos, relebrando acordos, dialocidade e meta de realização dentro do tempo estipulado até o final da aula;

- As considerações comparativas, bem como avaliações dos resultados foram realidas no sábado subsequente. Emergência surgida devido ao empenho do grupo, utilizando o tempo total disponibilizado para a realização do desafio.

\section{Figura 2 - Dois momentos da prática Artística do Desafio 2-COM diálogos}
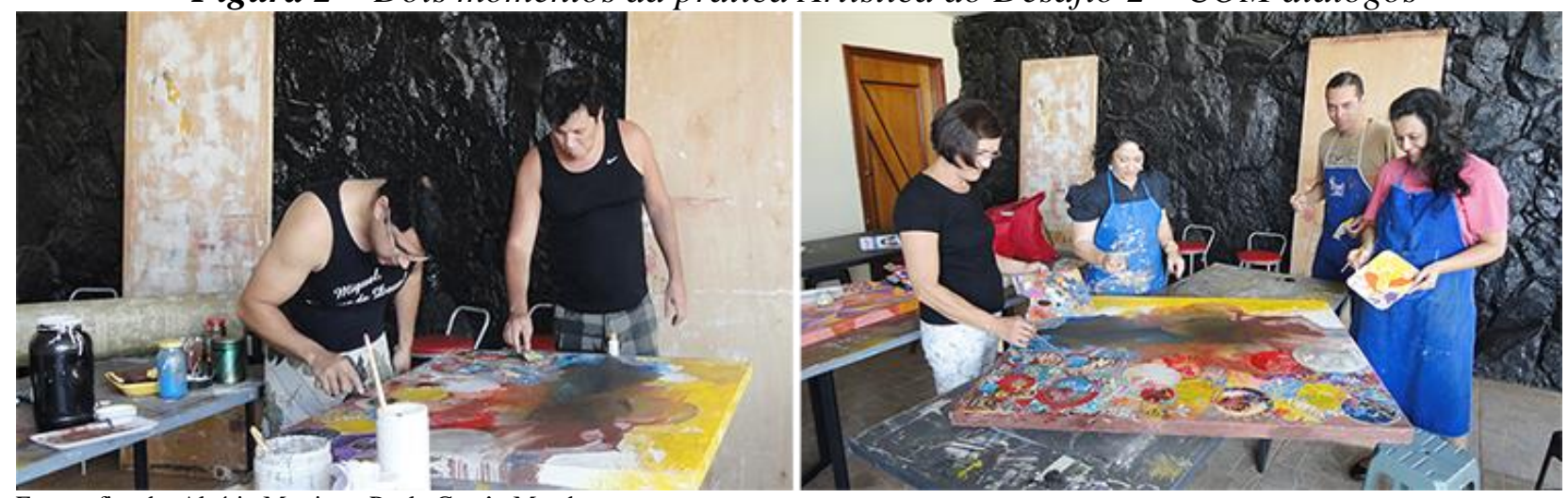

Fotografias de: Aluísio Martins e Paulo Corrêa Mendes 


\section{4 - RESULTADOS DA PRÁXIS DIALÓGICA ARTÍSTICA}

Inicialmente, observou-se dificuldade dos alunos-docentes em quebrar paradigmas do ensino "bancário" de conteúdos, sendo coparticipes do processo de educação. Reforçando a observação de Fritjof Capra (1995), “A mudança de paradigmas requer uma expansão não apenas, de nossas percepções e maneiras de pensar, mas também de nossos valores”. Portanto, a abertura dialógica que foi verificada em todos os momentos nos processos ensino e de aprendizagem, bem como, contextualização das relevâncias das teorias à prática da estratégia dialógica, ajudou na conscientização dos discentes, transpondo barreiras do ensino tradicional.

Os resultados obtidos, em geral, contou com o olhar atento do docente-facilitador e das suas intervenções mediadoras. Promotoras, aos alunos, de resoluções das complexidades dos diversos níveis de realidades em contextos diversos. Intervenções Mediadoras, para Feuerstein (1998), favorecem a aprendizagem significativa, que se dá pela mediação dialógica intencional interativa entre quem ensina (mediador) e quem aprende (mediado).

Tal atitude de abertura dialógica docente, intencional e planejada, favoreceu tipos de conversação de diálogos qualitativos. Fator primordial requerido nas conexões colaborativas, que favorece a compreensão das possibilidades para um mesmo fim.

Logo após a realização do Desafio 1, o diálogo naturalmente estartou. Com destaque para a dificuldade de não contar com contribuições sugestivas e autorizativas dos colegas para interferências na pintura de um na dos outros. Depois todos os membros do grupo passaram para análise do resultado estético da obra, bem como das ações dos protagonistas. Este diálogo interno e com os outros artistas-docentes perdurou mais tempo que a realização da própria obra.

Já no Desafio 2, verificou-se que, cada indivíduo traz consigo as vivências e experiências dos diversos níveis de realidade, bem como conhecimentos prévios à competências. Quando oportunizado abertura dialógica da participação colaborativa no construto educacional, com contexto significativo, os alunos ficam motivados, parceiros, coresponsabilizados e, por consequência, apreendem melhor. Além de criar um clima de harmonia entre os protagonistas.

A meditação propiciou no início da aula uma maior facilidade às ações nos processos de ensino-aprendizagem. Favoreceu a harmonização do indivíduo, bem como, o equilíbrio de energia do grupo, melhorou o foco nos objetivos e na transposição dos desafios. A meditação, 
uma ação pedagógica transdisciplinar, beneficia o acolhimento de si, do outro, do amor para com a parte e para com o todo. Ajuda no diálogo interno, em recorrência aos conhecimentos individuais prévios à competência desafiadora, ou seja, das epistemologias - dos saberes científicos de cada um dos protagonistas; da importância ontológica do ser ético e colaborativo; bem como, da preparação metodológicas à práxis de organização dos saberes internos e das necessidades de instrumentos necessários para sua colaboração artística.

A seguir, fotografia das obras realizadas. Para fins de evidências de resultados comparativos e, bem como, propósito didático analítico. De maneira geral, observamos maior força plástica do Desafio 2 (com diálogo). Além de ser uma obra com mais informações de técnicas, harmonia dos elementos, profundidade, explosão de cores.

Figura 3 - Resultados das pinturas coletivas: Des. 1, SEM diálogo; e Des. 2, COM diálogo.
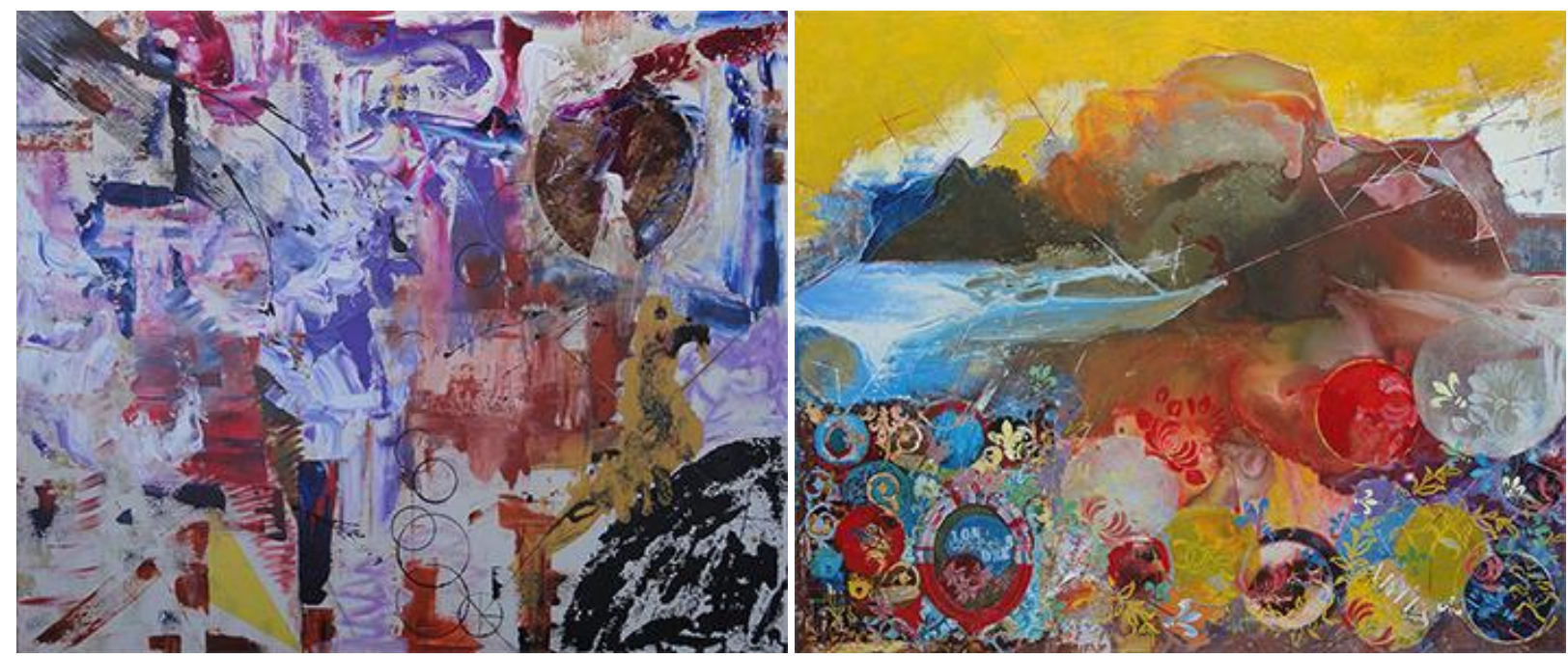

Fotógrafo: Paulo Corrêa Mendes

Obras executadas por: Aluísio Martins; Luciana Melo; Marcos Melkes; Rosa Banuth; Rodrigo Dantas; Rosana Barros;

Paulo Corrêa Mendes - docente-facilitador.

Dimensão de cada tela: $125 \times 100 \mathrm{~cm}$. Técnica: mista sobre telas. Ano de realização: 2015.

Na práxis artística do Desafio 2, a postura dialógica entre os protagonistas evidenciou competências dos protagonistas entre outros resultados significativos à formação integral e integrado do ser, em articulação com outras práticas didáticas transdisciplinares (meditação, mediação, acolhimento). Concernente a práxis da estratégia dialógica, observa-se:

- A compartilha dos saberes torna possível produzir novas idéias e visões sobre a realidade complexa, através de uma conexão com o particular e o geral, com as partes e a totalidade. Estreita relação com a definição de Morin (2000) para complexo “... aquilo que é tecido em conjunto";

- Com a abertura dialógica é possível produzir e compartilhar significados, ainda que 
extremamente diferentes ou até contraditórios;

- O resgate da subjetividade proposta pela didática transdisciplinar, ou seja, a percepção dos fenômenos e relato das vivências de todos, que evita simplificação e reducionísmo;

- O fortalecimento dos vínculos afetivos entre pessoas, bem como na melhoria da qualidade das interrelações sociais;

- Aceitação das diferenças e pensamentos divergentes, diminuíndo julgamentos prévios. Dificultadores das trocas, em todos os níveis, entre os seres humanos e, por conseguência, também, danoso ao meio ambiente;

- A prática melhora a comunicação qualitativa entre as pessoas, com escuta e fala atenta;

- A diminuição do automatísmo cartesiano, propagador da competição humana;

- O estímulo da conversação conscientes da vida em redes, bem como sua ampliação interconegtada;

- A ampliação do domínio técnico que o trabalhador deve possuir para o desempenho das competências requeridas pelo mundo do trabalho;

- O desenvolvimento de autonomia e mais iniciativa, nos desempenhos das ações diárias;

- O surgimento de responsabilidade e, também, consciência de sua relevância perpetuária das espécies.

Na realização dos cursos e dos programas de formação docente, criativamente, é possível respeitar as diretrizes dos documentos do projeto político-pedagógico das escolas profissionalizantes, bem como, obter resultados qualitativos educacionais na utilização da Estratégia Pedagógica da Práxis Dialógica Artística, integrando os pressupostos das teorias aqui apresentados ao ensino qualitativo na Educação Profissional.

\section{5 - DISCUSSÃO DA PRÁXIS DIALÓGICA ARTÍSTICA}

Condideramos que a autonomia, um pressuposto do ensino por competência, remete-nos a uma individuação. Válida, em parte, para reforçar a ideia da construção de si (autoformação). Mas, para o resgate de nossa humanização (pressuposto transdisciplinar), devemos considerar a importância dos diálogos consigo e também para com os outros. Reforça Paul (2013, p. 46) "a experiência de um pode às vezes servir ao outro". Assim, a nossa educação passa por momentos de abertura às contribuições do olhar do outro, de suas experiências e vivências (heteroformação). Passo evolutivo à consciência ecossistêmica (ecoformação), e reflexão formativa do ser em diferentes graus relacional do corpo e da alma (antroporformação).

Na medida em que avança o conhecimento sobre o ser humano, podemos perceber 
evidências de superações dos nossos limites. Na educação, parece que ao rompermos com a lógica objetiva binária da ciência moderna, evidenciamos a abordagem pedagógica da lógica transdisciplinar ternária, reconhecendo a importância da subjetividade e da intersubjetividade, ou seja, nas interações do sujeito com ele mesmo, com os outros e destes com os objetos por eles contituidos. Assim, segundo Paul (2008) “o modelo de formação a ser construído é, ao mesmo tempo, ontológico, fenomenológico e epistemológico, declinando-se em vários níveis de inteligibilidade". Tal consciência humana, acredita-se, ser a mais adequada para dar aporte educativo à complexidade hodierna. Afinal, somos seres regidos pela emoção nas condutas humanas, precedendo as decisões racionais às ações.

No Brasil, umas das organizações sociais mais desiguais e injustas, observa-se avanços consideráveis no texto da constituição de 1988, com reconhecimento dos direitos econômicos e sociais. Concernente à educação, em específico na educação profissional por competências, firmou-se o debate acerca da formação educacional integral do ser humano. Entretanto com algumas limitações do entendimento do que seja integritude do ser. Salvo alguns retrocessos, morosamente, avançamos mais na teoria do que na prática e insipidamente evoluímos na busca por soluções de resgate da inteireza do Ser. Felizmente, algumas vantagens surgiram de ordem ideológica: por uma nova ética individual, social e multicultural; por um viver colaborativo; por competência autônoma; por um viver criativo e mais simples; por mais honestidade, responsabilidade e compaixão; por uma consciência holística em prol da vida. Resgate da nossa humanidade amorosa, cooperativa, com consciência de si, do outro, no respeito a si, ao outro e para com a natureza. Entretanto, infelizmente, na dimensão prática, alerta-nos Morin (2001), ainda vivemos num mundo fragmentado e sob a égide do pensamento cartesiano que favorecem percepções desconectadas da realidade.

$\mathrm{Na}$ formação dos docentes, em novas competências, além dos fundamentos técnicos e científicos, capacidades técnicos e capacidades sociais, organizativas e metodológicas, devemos aprofundar no ensino de variadas estratégias pedagógicas, com ênfase na estratégia do diálogo. Lembra-nos Moraes (2012) para aprofundar no estudo do legado ético e coerente de Paulo Freire para o Brasil e o mundo, com sua pedagógia à transformação social, oportunizadora de liberdade consciente pela educação, que tem no diálogo acolhedor sua principal fundamentação. Apropriado aos enfrentamentos das mudanças paradigmáticas de toda ordem nas dimensões da vida e, por consequência a formação integral e integrado do ser humano. Articuladoras da tríade dos saberes: ontológicos, epistemológicos e metodológicos, capaz de religar às dimensões do ser. 
A abordagem transdisciplinar não é nova. Resgatamos de alguns filósofos antigos e aprofundamos no seu estudo prático antropológico, educativo e ecossistêmico, para enfrentar emergências paradigmáticas do mundo contemporâneo. Ao mundo profissional, traz vínculos de diálogos materializados no trabalho e suas interrelações sociais, indo além da autorregulação. Portanto, possuem uma natureza autopoiética, lembra-nos Maturana (1999) onde o indivíduo, a sociedade, a natureza e o cosmo se produzem e se autorregulam em acoplamento. Neste contexto, o diálogo educacional é mais que uma técnica didática. A prática transversal do diálogo em outras estratégias pedagógicas, traz uma visão de mundos, de tipos possíveis de relacionamentos e de colaborações processuais, construindo e reconstruindo mudanças.

Nas práxis didáticas transdisciplinares, aprendemos na reflexão quotidiana consciente, que os indivíduos transformam-se cônscios, quando envolvidos emocionalmente por meio de significados, criando compromisso com as atividades que se constroem e reconstroem sobre conexões naturais com os conhecimentos gerados em diálogos socioculturais, fora e dentro da escola. Nesta abordagem, o ser humano tem por característica a atividade autopoiética, ou seja, a autoprodução. Lebra-nos Maturana (2008), ao afirmar que alguns seres vivos são capazes de produzirem continuamente a si mesmos, sendo portanto em determinados momentos produtor e em outros, produto. Portanto, a práxis transdisciplinar artística servem à vida, pois oportuniza refletir às atividades, saberes experienciais e científicos, hierarquizandoos para compreender realidades do sujeito aprendente em eterna formação.

O fazer educacional precisa ser contextualizado, tanto nos pressupostos Freiriano, quanto Moriano e por desenvolvimento de Competências. Para tal, tendo como ponto de partida as relações colaborativas oportunizadas por diálogos. Escuta acolhedora de conhecimentos prévios, das realidades vividas contributivas a temática em pauta, aberta às emergências. Assim, a prática da estratégica didática transdisciplinar do diálogo desenvolve uma consciência crítica integral. Nesta conjuntura, é possível compreender melhor a afirmação:

[...] ensinar não é transmitir conhecimento. Para que o ato de ensinar se constitua como tal, é preciso que o ato de aprender seja precedido, ou concomitantemente, ao ato de aprender o conteúdo ou o objeto cognoscível, com que o educando se torna produtor também do conhecimento que lhe foi ensinado. (FREIRE, 1994, p. 118).

Na condução da Estratégia Pedagógica em Práxis Dialógica, o docente teve redobrar a atenção para não permitir diálogos tendenciosos, como de preferências religiosas, ideológicas, ou que sejam passíveis de interpretação preconceituosa de qualquer tipo. Este é um momento 
de integração colaborativa. Caso ocorra algum tipo de dispropósito de ação, deve aproveitar para conscientização de que somos humanos, diversos, complexos e com iguais direitos. Para tanto, entra em cena a abertura ao diálogo transversal em todos os processos de ensino aprendizagem.

A Estratégia da Práxis Dialógica Artística oportuniza a legitimação da convivência, o respeito a legitimidade do outro e interações que nos torna coensinantes e coaprendentes. Em específico, o fazer artístico permite reflexão dos diversos níveis de realidades do mundo, respeitando e valorizando diferenças, solidariedade, inteireza do momento presente, consciência das incertezas e certezas da condição humana.

A referida estratégia, pode ser aplicado nas primeiras aulas, tanto de Formação Docente, quanto em cursos de Educação Profissional, bem como ser adaptada para Educação Básica e Educação Fundamental. Uma estratégia que concomitante a outras, favorece os processos de ensino aprendizagem para o desenvolvimento da competências pretendidas. Ela supõe um aprendizado diário de docente e discentes em reaprender e confiar em novas didáticas articuladas na Educação Profissional.

\section{6 - CONSIDERAÇÕES FINAIS - provisórias}

Então, sabemos que, evoluímos com ganhos e perdas, pela inerência ao humano da busca por conhecimentos e da práxis do diálogo. Que na educação coletiva, com diálogo cuidadoso, cotidiana, ética e com visão ecossistêmica prolonga interconeções das partes com o todo e são, portanto, promotoras da vida em geral. Buscamos assim, o exercício de compreensão igualitárias de voz e condições na comunicação e no viver social, interligando às ciências com a arte e com a espiritualidade, sem supremacia dos saberes. Neste contexto, para uma digna sobrevivência, temos de entender que nossa origem e destino são os mesmos e dependem de um cuidar solidário, de acolhimento de si, do outro e da natureza, em contínuo aprendizagem com adaptabilidade, regeneração, sinergia e reciclagem.

Não temos dúvida que a educação, de maneira geral, promove mudanças estruturantes na transformação dos indivíduos, sendo responsável pela formação das inúmeras realidades no desenvolvimento de uma sociedade mais justa, crítica e igualitária. Para tanto, adquire paulatina flexibilidade e convergência a Educação formal, a Educação Profissional Técnica, as especializações e, a cultura geral. Pontua, Trigueiro (2000) das convergências de todas as estruturas sociais. "Unum versus alia" - uno feito do diverso. "o homem descobriu que sua 
inserção no mundo se faz como práxis - ação dentro e ao longo da qual ele se transforma e transforma o mundo". Em síntese, um jogo de fluidez articulativo para um novo paradigma de educação, que procura refletir o novo mundo posto, partindo de uma formação total do ser humano e permanente na vida. Assim, uma nova educação deve ser estruturada nos pressupostos do pensamento complexo e pela abordagem transdisciplinar, ambas as quais preconizam uma formação integral e integrado do ser humano.

Neste contexto, a conscientização do docente para desenvolver competências e a formação integral e integrado do sujeito perpassa o desenvolvimento de suas próprias competências, aprendendo e ensinando. Afinal docentes também aprendem quando ensinam. Portanto, uma formação docente promotora de um ambiente educacional que favoreça o questionamento, a argumentação, a pesquisa e a critica reflexiva. Que ajuda o aluno derrubar paradigmas para aprender a aprender, contribuindo na construção dos seus conhecimentos. Nesse sentido, é primordial que os saberes desenvolvidos tenham sentido para os alunos, estimulando habilidades tanto cognitivas como comportamentais, permitindo-lhes criarem soluções originais de forma inovadora, a partir de novos saberes que tenham aplicabilidade no contexto social e profissional.

Uma educação transdisciplinar, requer didáticas dialógica com abertura do coração para uma "trans-Formação" consciente. Isto implica em trabalhar a disciplina, a articulação entre as disciplinas e oportunizar o ir além das disciplinas ao encontro do sujeito. Esta pedagogia trabalha todas as dimensões humanas, do racional articulado com o emocional para acessar o nosso sagrado por meio de diferentes linguagens e formas expressivas da estética; música; dança; meditação e poesia. Afinal, a condição humana é múltipla e complexa, ou seja, somos sujeitos portadores de diferenciadas dimensões, por um contexto biológico, cultural, econômico, místico, psicológico. Nesta perspectiva, o diálogo promove interações das diversidades individuais e sociais, com inúmeras vivências ecoformadoras, oportunizando transformações para o resgate da essência do ser humano na e à vida.

Verificou-se que o movimento inicial de uma aula com a utilização da Estratégia Pedagógica da Práxis Dialógica Artística, pode constituir-se em mais uma forte práxis didática transdisciplinar. Um caminho que conduz para respostas às expectativas das complexas realidades nos tempos hodiernos à formação integral do sujeito. Uma nova vivência educacional, docente e discente, que permite uma ressonância de propósitos comuns. Acionandos por sentidos significativos na vida e à vida, de compaixão, acolhimento, respeito e amorosidade para com a parte e o todo. Esta abertura atenta às complexidades e diversos 
níveis de realidade na contemporaneidade, com maior significação, motivação e criatividade, alento para um novo mundo possível de esperança no ser humano e no futuro do planeta que devem ser alimentado por utopias e sonhos, estimulados em sala de aula para serem materializadas. Portanto, o fazer artístico na educação oportuniza a interdisciplinaridade e a transdisciplinaridade como respostas contemporâneas para a articulação dos saberes.

$\mathrm{Na}$ convivência, o sistema vivo e o meio se modificam de forma congruente, onde o meio produz mudanças na estrutura desses sistemas, que por sua vez agem sobre o meio, alterando-o, numa relação circular. O exercício do aprendizado do diálogo deve ser favorecido no cotidiano escolar. Favorecendo significativa melhora nas relações sociais escolares, na vida familiar, nas participações socioculturais, e até consigo mesmo. Colaborativa em âmbito maior ao favorecimento dos contatos relacionais entre instituições, culturas e países. Portanto, o diálogo aqui é qualificado como dialógico acolhedor do outro. $\mathrm{O}$ indivído que é educado por esse tipo de diálogo, aceita o outro, fortalece ligações e aprofunda as percepções que temos delas. Para a dialógica proposta, o ouvir e tão importante quanto a fala. O primeiro exercício essencial é o de reaprender a ouvir o outro e empaticamente. Esse tipo de escuta atenta e amorosa contribui com a qualidade da fala em construção e atinge resultados compartilhados e facilitadores da escuta do mundo, de diálogo com o mundo.

Aprender a dialogar é religar com nossa essência humana e requer aprendizado dioturno, consciente. Compostos por uma série de ações agrupadas em alguns passos principais:

- Identificar e reduzir os entraves habituais mentais que broqueiam a capacidade de saber ouvir do indivíduo. Ações que podemos exemplicar como: automatismos sem reflexões, preferências indiviualístas competitivas, entre outras;

- Buscar alternativas de novo modelo mental de comunicação que considera às referências experienciais direta. Com ações de saber ouvir atentamente o outro, de maior capacidade de observar sem preconceitos, de ética do respeito, de colaborações significativas, de consciência silenciosas dos diversos níveis de realidades.

- Aprender a saber falar qualitativo, ou seja, a fala que busca unir. A beleza do diálogo tem com característica aproximar indivíduos, fortalecer os vínculos sociais a partir das vivências. Ações de abertura às emergências de ideias novas com fala que permite dialogar, percebendo e pensando de forma diferente, de repensar nossas certezas por ângulos diferentes.

Não existe apenas uma receita simples para aprender a ensinar nessa nova concepção educativa paradigmática transdisciplinar. Acreditamos que outras estratégias pedagógicas, além da aqui investigada, da práxis dialógica e artística, ajudam a romper com o modelo 
educacional, cartesiano, depositório de conteúdos e sem significação, ou seja, um agrupamento de assuntos para memorizar ou exercícios para praticar à exaustão, enfadonhos, portanto, sem nenhum significado motivacional durante os processos de ensinoaprendizagem.

Esta foi uma experiência válida, mas com suas limitações e portanto não é conclusiva. Tratou-se de uma pesquisa-ação de caráter de verificação de uma experiência em estratégia pedagógica, baseada em documentos, análise bibliografia e numa construção unilateral para capacitações docentes à Educação Profissional. Recomenda-se para estudos futuros que seja feita uma pesquisa empírica para observação e aplicação de instrumentos capazes de medir a diferença de resultados em outros cursos que apliquem a mesma proposta pedagógica paradigmática educacional. Afinal, o ser humano é complexo, com inúmeras possibilidades de níveis de realidade relacional com o ecossistema.

\section{REFERÊNCIAS BIBLIOGRÁFICAS}

ARNT, Rosa Maria \& MORAES, Maria Cândida \& BATALLOSO NAVAS, Juan Miguel (organizadores). Complexidade e Transdisciplinaridade em Educação: teoria e prática docente. Rio de Janeiro: WAK editora, 2010.

Brasil. (1996). Lei de Diretrizes e Bases da Educação Nacional - Lei no 9.394. Brasília.

. (1999b). Parecer 16/99 - Diretrizes Curriculares Nacionais para a Educação Profissional de Nível Técnico. Brasília, 1999.

CAPRA, Fritjof. A Teia da Vida: uma nova compreensão científica dos sistemas vivos. São Paulo: Editora Cultrix, 1995.

DELORS, Jaques. Educação: um tesouro a descobrir. São Paulo: Cortez; Brasília: MEC/UNESCO, 1998.

FEUERSTEIN, Reuven. Definicion of essencial concepts and terms: a working glossary. Jerusalen: ECELP, 1998.

FREIRE, Paulo. Pedagogia do Oprimido: 27ª Edição. São Paulo: Editora Paz e Terra, 1987.

. Professor sim, tia não: Cartas para quem gosta de ensinar. São Paulo: Olhos d’Água. 1994.

. Pedagogia do da Autonomia: saberes necessários à prática educativa. São Paulo: Editora Paz e Terra, 1998.

. Pedagogia da indignação: cartas pedagógicas e outros escritos. São Paulo: Unesp, 2000.

MARIOTTI, H. As Paixões do Ego: Complexidade, política e solidariedade. São Paulo: Editora Palas Atenas, 2000.

MATURANA, Humberto. Formação Humana e Capacitação. Petrópolis, RJ: Editora Vozes, 2008.

MORAES, Maria Cândida. Educar na Biologia do Amor e Solidariedade. Petrópolis, RJ: Vozes, 2003.

MORAES, Maria Cândida. Ecologia dos Saberes: complexidade e, transdisciplinaridade e educação. 
Novos fundamentos para iluminar, novas práticas educacionais. São Paulo: Antakarana/Willis Harman House, 2008.

MORAES, Maria Cândida; BATALlOSO, Juan Miguel. (Cood.) Complexidade e Transdisciplinaridade em Educação. Rio de Janeiro: Wak, 2010.

MORAES, Maria Cândida; BATALlOSO, Juan Miguel; VIEIRA, Adriano José Hertzog (orgs). A esperança da pedagogia: Paulo Freire - consciência e compromisso. Brasília: Editora Liber, 2012.

MORIN, Edgar. O Paradigma Perdido: a natureza humana. Sintra, Portugal: Publicações Europa América, 1990.

Introdução ao Pensamento Complexo. Lisboa: Instituto Piaget, 1999.

A Inteligência da Complexidades. São Paulo: Petrópolis, 2000.

Os Sete Saberes Necessários à Educação do Futuro. São Paulo: Cortez, 2001.

. A cabeça bem-feita. Repensar a reforma, reformar o pensamento. 15. ed. Rio de Janeiro: Bertrand Brasil, 2008.

NICOLESCU, Basarat et al. Educação e transdisciplinaridade II. Brasília: UNESCO, 2002.

PASCAL, Blaise. Pensamentos. Tradução de Louis Lafuma. São Paulo: Martins Fontes, 2001.

PAUL, Patrick. Formação do Sujeito e Transdisciplinaridade História de vida profissional e imaginal. Tradução: Marly Segreto. Editora Triom. São Paulo, 2008.

. Saúde e Transdisciplinaridade. Tradução de Marly Segreto. São Paulo: Editora da Universidade de São Paulo, 2013.

RIBEIRO, Milton. Planejamento Visual Gráfico. $7^{\text {a }}$ ed. Brasília: Linha Gráfica Editora, 1998.

Serviço Nacional de Aprendizagem Industrial. Departamento Nacional. Metodologias SENAI de Educação Professional - Perfil Profissional; Desenho Curricular; Prática Docente. Brasília: SENAI/DN, 0112013.

SUANNO, Marilza \& RAJADELL, Núria (orgs). Didática e Formação de Professores: perspectivas e inovações. Editora da PUC Goiás. Goiânia, 2012.

TRIGUEIRO, Durmerval. Um novo mundo, uma nova educação. Revista Brasileira de Estudos Pedagógicos, Rio de Janeiro, v.81, n. 199, p.501-510, set/dez. 2000. 